\title{
TERAPIA FOTODINÂMICA: ASPECTOS FARMACOLÓGICOS, APLICAÇÕES E AVANÇOS RECENTES NO DESENVOLVIMENTO DE MEDICAMENTOS
}

Fernanda Ibanez Simplicio, Florângela Maionchi e Noboru Hioka*

Departamento de Química, Universidade Estadual de Maringá, Av. Colombro, 5790, 87020 - 900 Maringá - PR

Recebido em 11/7/01; aceito em 10/12/01

\begin{abstract}
PHOTODYNAMIC THERAPY: PHARMACOLOGICAL ASPECTS, APPLICATIONS AND NEWS FROM MEDICATIONS DEVELOPMENT. Photodynamic Therapy (PDT) is a clinical procedure, which utilize a photosensitive compound and light. This is a new modality of treatment for cancer, aged related macular degenerescence (AMD), psoriasis, arthritis, arterial restenosis, etc which exhibits efficiency, less traumatic effects, low recovery time and few co-lateral effects. The first officially approved drug for PDT by the Food and Drug Administration (EUA) is Photofrin ${ }^{\circledR}$, which is applied for cancer. A new generation drug for PDT, Visudyne ${ }^{\circledR}$ was recently approved to treat AMD; its photoactive compound is BPDMA, a benzoporphyrin mono-acid derivative (chlorin-type molecule). A concise history, technical information and some drugs for PDT are reported.
\end{abstract}

Keywords: photodynamic therapy; visudyne; tumor.

\section{INTRODUÇÃO}

Tumor, sinônimo de neoplasma ou blastoma, é o crescimento anormal de tecidos. Células doentes, com um distúrbio genético, passam a se reproduzir mais rapidamente do que as células normais levando à formação do tumor, podendo este ser benigno ou maligno. Quando o crescimento do tumor é muito acelerado, desorganizado e com tendência a se alastrar a outros órgãos, geralmente é maligno. Câncer é a designação genérica de qualquer tumor maligno; a palavra câncer é derivada do latim e significa caranguejo. O nome é decorrente da facilidade com que este crustáceo tem de se aderir firmemente em qualquer lugar, assim como o tumor se adere a um local do corpo humano em que se desenvolve $e^{1,2}$. Os tipos mais comuns de câncer são os de pele, mama feminina, próstata, pulmão e estômago sendo que os últimos quatro são letais e compõem a segunda maior causa de mortes por doenças no Brasil ${ }^{3}$. Entre os citados, o câncer de pele é o de maior incidência no país, porém, com exceção do câncer melanoma, é a variedade de menor letalidade ${ }^{3}$.

Diante dos graves efeitos colaterais e da eficiência limitada das terapias tradicionais (cirurgia, quimioterapia e radioterapia) outras alternativas estão sendo constantemente propostas na área de oncologia (cancerologia). Dentre estas destaca-se a terapia fotodinâmica (TFD), uma modalidade relativamente nova no tratamento de câncer. Apesar de boa parte do uso da TFD ser centrada nesta doença, outras moléstias tais como degeneração macular da retina, psoríase, artrite reumatóide sistêmica, restenosis, micoses fungóides, infestações bacterianas, verrugas, arteriosclerose, AIDS, etc têm como característica comum um crescimento anormal de tecidos igualmente ao câncer ${ }^{4-6}$. Assim a TFD está sendo usada e investigada em nível mundial no tratamento dessas e outras doenças correlatas na origem.

A combinação droga mais luz forma a base da TFD. Um composto fotossensível é introduzido no paciente e se acumula preferencialmente em células que se reproduzem rapidamente. Essas são posteriormente irradiadas, via laser através de um cateter de fibra óptica, junto ao tecido doente. A luz (tipicamente 600 a $800 \mathrm{~nm}$ ) ativa o composto, gerando formas de oxigênio tóxicas que necrosam ou afetam convenientemente o tumor, levando-o ao colapso e à ação curativa do paciente. Em certos casos, onde a cirurgia do tumor é complexa devido ao seu tamanho ou ao acesso, recomenda-se a aplicação da TFD como tratamento pré-operatório para promover a diminuição do mesmo ${ }^{5}$.

Evidentemente uma das características necessárias no tratamento é que as drogas possuam toxicidade baixa no escuro e tendência elevada a acumular-se no tecido doente, evitando-se que a vizinhança acidentalmente iluminada seja danificada ${ }^{4,5,7}$.

Apesar de diversos tipos de compostos fotossensíveis terem sido intensamente investigados, o primeiro a ser aprovado pelas autoridades de saúde para tratamento de câncer através da TFD foi um derivado de hematoporfirina $\left(\text { Photofrin }^{\circledR}\right)^{5}$. Posteriormente, o medicamento Levulan ${ }^{\circledR}$ Kerastick foi aprovado para tratamento de lesões na pele ${ }^{7}$. Recentemente outro fármaco, uma benzoporfirina (Visudyne ${ }^{\circledR}$ ), obteve liberação de uso ${ }^{7}$. Entretanto, neste caso, a droga foi aprovada somente para combater a degeneração macular da retina do tipo predominantemente clássica, uma doença relacionada à idade e que afeta $40 \%$ do total de pessoas acima de 75 anos.

A degeneração macular, cuja causa real é desconhecida, pode ser classificada em dois tipos: a não exsudativa (ou "seca") e exsudativa (ou "molhada"). Embora os dois sejam progressivos e geralmente bilaterais, diferem em termos de suas manifestações, prognósticos e conduta $^{8,9}$. A forma exsudativa, embora represente somente cerca de $15 \%$ do total de casos, é a mais agressiva e é a responsável por aproximadamente $80 \%$ do total de pessoas cegas em países industrializados. A degeneração macular exsudativa é provocada pelo aparecimento de vasos sanguíneos extraordinários (coriocapilares), sob o centro da retina (mácula), processo chamado de neovascularização da coróide (NVC). Esses vasos apresentam pequenos defeitos nas paredes que provocam o extravazamento de sangue, prejudicando a mácula ${ }^{8-10}$. A mácula é a responsável pela visão central, aquela que permite, por exemplo, ler, escrever, dirigir, reconhecer rostos, etc. Antes da técnica de TFD, o tratamento mais eficaz consistia em queimar esses vasos através de laser térmico, com indesejável queima parcial da retina e com possibilidade de reincidência ${ }^{8}$.

A TFD com o medicamento Visudyne ${ }^{\circledR}$ já está sendo aplicada no Brasil através da Escola Paulista de Medicina - setor de oftalmolo-

\footnotetext{
*e-mail: nhioka@uem.br
} 
gia9 . Além do uso em degeneração macular da retina do tipo predominantemente clássica, o medicamento está sendo avaliado para o tratamento de outras moléstias na mácula, como por exemplo, a miopia patogênica ${ }^{10}$.

O objetivo do presente trabalho é contribuir para a divulgação da modalidade médica conhecida como terapia fotodinâmica e apontar os mais recentes avanços no desenvolvimento de medicamentos para essa área, destacando-se particularmente o Visudyne ${ }^{\circledR}$. Esse medicamento produziu um grande impacto nos meios médicos e testes clínicos indicam sucesso também no tratamento de tumores e outras moléstias ${ }^{4,6,9,10}$. Dessa forma, deseja-se que, num futuro próximo, o trabalho conjunto de químicos, físicos, médicos, biólogos, bioquímicos, etc, consiga fazer com que a TFD seja utilizada como técnica rotineira nos centros médicos do país, permitindo a cura de alguns tipos de câncer, doenças na mácula e outras.

\section{UM BREVE HISTÓRICO DA TFD}

Na introdução, usou-se o termo "relativamente nova" para a técnica da TFD, porque há mais de 4.000 anos atrás os egípcios deram início a essa terapia, através da ingestão de plantas (contendo os psoralenos, furo[3,2-g]-coumarina ou ácido 6-hidroxi-5-benzofuranoacrilico $\delta$-lactona) e luz solar, para tratar doenças como o vitiligo ${ }^{11,12}$. Entretanto, a técnica começou a ser empregada com sistemática científica apenas bem recentemente.

Em 1900, Raab descreveu a ação de corantes acridina e luz solar sobre Paramecia, demonstrando que este organismo unicelular pode morrer sob essas condições ${ }^{13}$. Finsen, em 1901, apontou que a radiação solar poderia ser utilizada na cura de Lupus vulgaris ${ }^{14}$. Em 1903, Trappeiner utilizou a aplicação tópica do corante eosina e exposição à luz para o tratamento de um câncer de pele ${ }^{15}$. Em 1913 Meyer-Betz fez uma auto-injeção de $200 \mathrm{mg}$ do que ele pensava ser hematoporfirina pura e não sentiu nenhum efeito, porém ao se expor à luz teve fotossensibilidade na pele por vários meses ${ }^{12}$. Policard, em 1925, estudou porfirinas objetivando a produção de efeitos fototóxicos em tecidos, principalmente em tumores malignos ${ }^{12}$. A história da chamada primeira geração de drogas para a TFD, à base de derivados hematoporfirínicos, começa com Schwartz no início da década de 50. Ele mostrou que nos experimentos de Meyer-Betz, o princípio ativo não era a hematoporfirina (pois esse composto é facilmente eliminado do organismo), mas na realidade tratava-se de uma mistura de diversas substâncias oligoméricas provenientes do método original de síntese e isolamento da mesma ${ }^{12}$. Schwartz enriqueceu a mistura de oligômeros (chamou o preparado de HpD) e Lipson, sob orientação de Schwartz na década de 60, investigou o acúmulo preferencial deles em tumores, implantados em camundongos e ratos e observou que a incidência de luz proporcionava regressão da doença $^{12}$. Como resultado desses estudos, no final da década de 60, Lipson obteve sucesso no tratamento de uma mulher que possuía câncer de mama usando HpD e irradiação seletiva do tumor, marcando assim, o início da TFD como terapia clínica para câncer ${ }^{16}$.

A partir da década de 70, várias preparações de derivados porfirínicos começaram a ser testadas para uso em TFD, culminando com o desenvolvimento do Photofrin $\mathrm{II}^{\circledR}$ (refinamento do HpD) por Dougherty ${ }^{17}$. Posteriormente, no fim da década de 80, a empresa QLT Inc. através de purificações e otimizações do preparado anterior, via processos de liofilização, chegou ao medicamento Photofrin ${ }^{\circledR}$ (no ano de 2000, a QLT vendeu a marca do seu produto para a Axcan Scandipharm Inc) ${ }^{18}$. A QLT é uma empresa de alta tecnologia, cuja diretoria é composta por diversas pessoas provenientes do meio acadêmico, com sede na cidade de Vancouver, Canadá. Nesta localidade, igualmente, situa-se a University of British Columbia (UBC), instituição de ensino onde a associação indústria-universidade é das mais profícuas ${ }^{19}$. O Photofrin ${ }^{\circledR}$ é o único medicamento aprovado pela FDA/EUA (Food and Drug Administration) para o tratamento do câncer com a técnica de TFD (aprovação datada de 22 de dezembro de 1998). Outros países, onde o uso da droga também foi aprovado, são: Canadá, Alemanha, França, Japão e Brasil. Os fármacos, preferencialmente, devem ser compostos únicos e não misturas complexas, uma vez que simplificam os estudos entre o princípio ativo e o efeito terapêutico, acarretando em predisposição bem maior à aprovação clínica pelas autoridades de saúde. Por essa razão, a aprovação do Photofrin ${ }^{\circledR}$ foi dificultada inicialmente, por se tratar de uma mistura de diversos compostos; entretanto, diante da variabilidade no grau de incorporação de substâncias ao tumor, essa alegação, aliada à baixa ocorrência de efeitos colaterais, foi utilizada como arma favorável à aprovação final ${ }^{12}$.

A busca de novas drogas fotossensíveis, a chamada segunda geração, levou a compostos que apresentaram melhorias nas propriedades foto-físicas em relação ao Photofrin ${ }^{\circledR}$. Embora de baixo impacto para a área médica, em 7 de dezembro de 1999, a FDA aprovou o uso do Levulan ${ }^{\circledR}$ Kerastick, uma pró-droga (composto base que irá produzir o princípio ativo) para lesões de pele na face e escalpo $^{20}$ (ver detalhamento adiante). De significante impacto foi a recente aprovação do medicamento Visudyne ${ }^{\circledR}$, desenvolvido pela empresa QLT Inc. em associação com a University of British Columbia, sob supervisão do Professor Dr. D. Dolphin ${ }^{21}$. O principio ativo é o composto BPDMA, uma benzoporfirina que na forma injetável foi batizada de verteporfina ${ }^{\circledR}$. O medicamento, aprovado para o tratamento de degeneração macular, também está sendo testado pela QLT e UBC na terapia do câncer, AIDS e demais doenças já mencionadas. Atualmente a empresa responsável pela comercialização do produto, junto com a QLT, é o braço da Ciba Vision, Novartis Ophthalmics. Visudyne ${ }^{\circledR}$ foi aprovado pelas autoridades de saúde da Suíça (16 de dezembro de 1999), EUA / FDA (12 de abril de 2000) e Grã-Bretanha / União Européia (28 de julho de 2000).

\section{PROCEDIMENTO CLÍNICO}

A TFD é adequada para tumores médios e pequenos e no caso de degeneração macular predominantemente do tipo clássica - "molhada”. Para a aplicação da técnica, após diagnóstico e avaliação rigorosa do problema clínico, o medicamento no estado sólido é solubilizado em água ou soro fisiológico. A solução resultante é administrada intra-venosamente e o terapeuta, após aguardar o tempo recomendado (onde se tem o maior acúmulo do fármaco no tecido doente), efetua a iluminação (Esquema 1). O processo de infusão da droga deve ser lento e cuidadoso diante da possibilidade de extravasamento devido à fragilidade da parede celular das veias, especialmente de idosos. Caso o extravasamento ocorra, a área deve ser protegida da luz direta até que o inchaço e a coloração desapareçam. Para o tratamento de pele, a infusão da droga ocorre por via tópica.

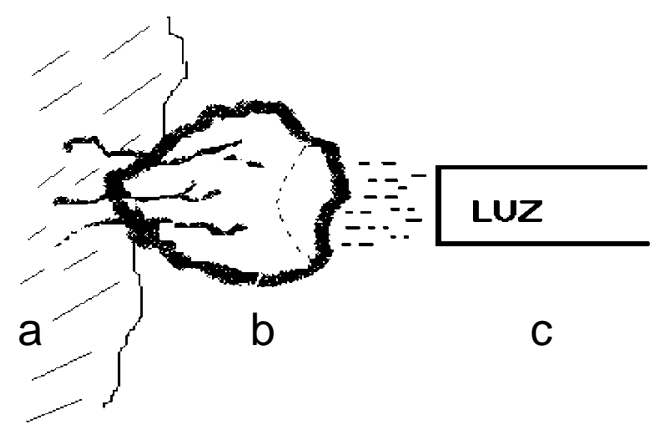

Esquema 1. (a) Tecido; (b) Tumor; (c) Laser 
As quantidades aplicadas de medicamento e as características do laser (tipo, dosagem de potência e tempo de iluminação) dependem da droga que está sendo aplicada e da espécie e gravidade da doença tratada $^{22}$

Após a irradiação verifica-se que, em geral, não ocorre a destruição total do tumor. Apenas a região fotolisada fica necrosada, porém o efeito é propagado, acreditando-se que a morte do tecido decorre, principalmente, através do comprometimento do sistema vascular, ou seja, do sistema de irrigação tumoral (que transporta os nutrientes necessários ao crescimento rápido do tumor).

\section{CARACTERÍSTICAS GERAIS NECESSÁRIAS ÀS DROGAS USADAS EM TFD}

Algumas propriedades gerais que os compostos e seus formulados devem possuir são listadas abaixo ${ }^{12}$ :

i) características fotofísicas favoráveis;

ii) baixa toxicidade no escuro (baixa citotoxicidade);

iii) fotossensibilidade não prolongada;

iv) simplicidade na formulação, reprodutibilidade e alta estabilidade do formulado (tempo mínimo de 2 anos) que, geralmente, é mantido seco, bastando ao médico adicionar água ou soro fisiológico e agitar;

v) farmacocinética favorável (rápida eliminação do corpo);

vi) facilidade de manuseio sintético que permita efetuar modificações para otimizar as propriedades desejáveis;

vii) facilidade de obtenção em escala industrial a custos reduzidos e com boa reprodutibilidade;

viii) facilidade de análise total dos componentes da fórmula, inclusive com fornecimento de roteiros de validação e

ix) alta afinidade e penetração no tecido doente em detrimento do tecido saudável (seletividade).

É importante frisar que o medicamento deve atender a esse conjunto de propriedades gerais para ser considerado uma droga comercialmente viável e eficaz na sua ação terapêutica. Daí advém a importância da formulação empregada.

Quanto às características fotofísicas favoráveis, um fator importante é o comprimento de onda da luz necessária à foto-excitação do composto. Na região visível, quanto maior o comprimento de onda da luz incidente, maior é o seu grau de penetração no tecido. Radiação de comprimento de onda menor sofre maior espalhamento e a presença de cromóforos endógenos nos tecidos, que absorvem em comprimentos de onda menores, principalmente a hemoglobina, faz com que a penetração de luz seja menor ${ }^{23}$. Quanto maior a penetração de luz, maior a eficiência no combate ao tecido doente, possibilitando, também, o tratamento de tumores maiores. Portanto, as drogas desenvolvidas para uso em TFD devem ser corantes (cromóforos) que absorvam na região próxima ao infra-vermelho ${ }^{4,24}$. Acima de 800 nm ocorre a absorção da radiação pela água, o que restringe o comprimento de onda a este limite superior. No caso de porfirinas e seus similares a excitação é realizada através da banda $Q$.

Quando a droga já se encontra acumulada no tecido doente, efetua-se a irradiação, dosada e seletiva, levando a molécula a um estado singlete excitado $\left({ }^{1} \mathrm{~S}^{*}\right)$. Desse estado a molécula irá sofrer processos simples de desativação por colisão ou fluorescência (mecanismos desfavoráveis à TFD), ou reagir com substratos biológicos, ou sofrer o processo não radiativo de conversão entre sistemas levandoa a um estado triplete $\left({ }^{3} \mathrm{~T}\right)$, com posterior reação com moléculas do sistema biológico. O processo de reação direta da molécula no estado ${ }^{1} \mathrm{~S}^{*}$ com substratos biológicos é chamada de TFD do tipo I, enquanto que a via estado triplete é chamada de TFD tipo II. Segundo a literatura, os compostos citados neste trabalho seguem o mecanis- mo tipo II, porém não se descarta a possibilidade de ocorrerem os dois mecanismos nos sistemas biológicos ${ }^{22,25}$.

$\mathrm{O}$ composto no estado ${ }^{3} \mathrm{~T}$ perde a energia adicional através de três diferentes maneiras: via fosforescência, via colisão ou via processo não radiativo pela troca de spin com outra molécula igualmente no estado triplete. Como o processo de fosforescência é proibido, o tempo de vida do estado triplete é relativamente grande, o suficiente para permitir a supressão de energia por colisão com o oxigênio $\left({ }^{3} \mathrm{O}_{2}\right)$. Sabe-se que a presença de oxigênio molecular é parte fundamental ao processo de $\mathrm{TFD}^{4,26}$, e que este oxigênio (triplete) ao suprimir a energia do sensibilizador $\left({ }^{3} \mathrm{~T}\right)$ irá gerar oxigênio singlete $\left({ }^{1} \mathrm{O}_{2}\right)$. Essa espécie, altamente reativa, tem tempo de vida em água de aproximadamente $4 \mu \mathrm{seg}$ (em sistemas biológicos esse tempo cai para abaixo de $0,04 \mu \mathrm{seg})^{22}$. $\mathrm{O}^{1} \mathrm{O}_{2}$ pode efetuar várias reações com substratos biológicos, como oxidação e ciclo-adição principalmente com sítios de elevada densidade eletrônica (tais como colesterol, triptofano, guanina, cadeias laterais de amino-ácidos contendo estruturas aromáticas e enxofre, ligações duplas de esteróides e lipídios insaturados ${ }^{12,22}$, levando à interrupção de processos biológicos. Contudo, não existe certeza absoluta de que o oxigênio singlete seja o responsável pela fototoxicidade, uma vez que este leva à formação de radicais livres tais como: o ânion superóxido $\left(\mathrm{O}_{2}{ }^{-}\right)$, hidroxil $(\mathrm{OH})$ via reação de Fenton, e peróxido de hidrogênio $\left(\mathrm{H}_{2} \mathrm{O}_{2}\right)^{25}$. De qualquer forma, um dos primeiros testes efetuados no desenvolvimento de novas drogas é investigar a sua habilidade em formar oxigênio singlete.

Um processo adicional que o sensibilizador (droga) sofre é o de foto-branqueamento, causado por modificações na estrutura da molécula através de reações paralelas. O sentido do termo foto-branqueamento é o de que a molécula sofrerá reação e o produto não irá mais absorver luz no comprimento de onda de incidência, deixando assim de exercer sua ação terapêutica.

Dessa forma, as primeiras propriedades fotofísicas in vitro investigadas em moléculas candidatas para a TFD são ${ }^{12}$ :

i) forte absorção de luz na região acima de $650 \mathrm{~nm}$, onde a luz apresenta maior penetração no tecido;

ii) alto rendimento quântico de estado triplete;

iii) alto rendimento quântico de geração de oxigênio singlete e

iv) baixo rendimento de reação de foto-branqueamento do cromóforo.

\section{AUTO-AGREGAÇÃO, SELETIVIDADE E FORMULAÇÃO}

Apesar da importância dos resultados de testes in vitro, freqüentemente verifica-se alterações significativas nas características dos compostos em sistemas in vivo, havendo a necessidade de testes em cobaias para uma rigorosa avaliação clínica ${ }^{26,27}$. Curiosamente, o contrário também pode acontecer, pois compostos como MACE e m-THPC (discutidos abaixo) exibiram resultados fracos nos testes in vitro, porém demonstraram-se clinicamente efetivos ${ }^{12}$.

Para a análise in vivo torna-se necessário discutir uma questão central que é a relação entregador/distribuidor da droga. Em compostos como o BPDMA um fator que estimula seu acúmulo na célula é sua alta hidrofobicidade, entretanto essa propriedade, em meio aquoso, leva à auto-agregação e em muitos casos a uma subseqüente precipitação. Em geral atribui-se ao agregado a forma dimérica ${ }^{26,28-30}$. A agregação reduz drasticamente a capacidade do composto de gerar oxigênio singlete; desse modo é necessário que o princípio fotoativo apresente-se solubilizado e na forma monomérica. Essa característica deve ser obtida imediatamente após o terapeuta provocar a mistura do fármaco com água (ou soro fisiológico), o que evita também a possibilidade de agregados maiores provocarem dor no momento da injeção e mesmo a morte do paciente, através de entu- 
pimento de artérias por precipitados. Essa estabilização da espécie monomérica deve ser obtida principalmente pela formulação adequada da droga.

Uma vez discutido o problema da agregação, abordar-se-á a questão da seletividade. A maioria das drogas funciona porque sua constituição e conformação permitem ligar (e possivelmente reagir) com um sítio celular único. Pequeníssimas variações na estrutura ou conformação reduzem, ou eliminam, suas propriedades terapêuticas. Felizmente, as drogas para TFD usadas até o momento não precisam se ligar a um receptor único e específico ${ }^{24}$. Salvo nos casos de tratamento de pele, como citado anteriormente, a administração da droga é efetuada por injeção intravenosa, sendo fundamental investigar o problema da biodistribuição.

Alguns derivados porfirínicos exibem alta afinidade por lipoproteínas de baixa densidade (LDL) do fluxo sanguíneo e, como extensamente documentado, tecidos em metástase possuem alta concentração de receptores deste tipo de lipoproteína (em comparação com células normais). Esta propriedade promove um maior acúmulo do fármaco no tecido doente. No caso do Photofrin ${ }^{\circledR}$ vários órgãos e tecidos eliminam-no em 40 a $72 \mathrm{~h}$, mas tumores, pele e órgãos como o fígado e o baço, retêm o fármaco por tempo maior. No caso de degeneração macular, as células endoteliais em proliferação (neovascularização da coróide) também apresentam elevado número de receptores de LDL. Dessa forma, no caso do Visudyne ${ }^{\circledR}$, o complexo BPDMA - LDL é rapidamente absorvido.

$\mathrm{Na}$ realidade, órgãos como fígado e rim também apresentam alta taxa desses receptores, portanto um ponto crucial na TFD é o balanço entre a distribuição da droga e o tempo de espera para o início da irradiação, de tal modo que a concentração da droga e o grau de profundidade no tecido doente sejam adequados ${ }^{5,7}$. O ajuste do tempo de circulação no fluido sangüíneo pode ser realizado através de componentes da formulação, aumentando a eficiência terapêutica através de uma biodistribuição da droga em favor de tecidos patogênicos e evitando a toxicidade em tecidos sadios. Apesar do citado, a distribuição do fármaco ainda é um fator limitante. Por outro lado, a tendência da droga em se distribuir nos diversos tecidos, incluindo-se aí os patogênicos, permite, através do direcionamento da luz, um ajuste na seletividade. Algumas formulações são discutidas a seguir.

Fármacos hidrofóbicos podem ser posicionados em ambientes lipofílicos e solubilizados em água, através de formulados lipossômicos, por exemplo. Estas estruturas coloidais são um dos mais versáteis grupos de carregadores para drogas, pois, além de solubilizá-las mantendo as suas características físico-químicas, entregam-nas seletivamente. Os lipossomos são, geralmente, formados a partir de fosfolipídios (há uma enorme variedade disponível, entre artificiais e sintéticos) que, por sua vez, apresentam alta afinidade por bicamadas celulares. O grau de incorporação, farmacocinética e entrega de compostos à célula pode ser ajustado, contudo a interação droga - lipídio dentro da bicamada é complexa. Por outro lado, com alguns fármacos é preferível liberação rápida (segundos) para a fração lipoprotéica do plasma, isto é, ter-se-ia um carregador in vivo, o que asseguraria uma alta concentração circulatória inicial e, portanto, um maior gradiente de concentração através do endotélio.

Lipossomos podem ser formados por mistura de anfifílicos, por exemplo, dimiristoil fosfatidil colina e derivados de fosfatidil glicerol insaturados e preparados na formulação através da técnica de filme fino, fármaco : fosfolipídio, ou seja, ambos são dissolvidos num solvente volátil adequado que, posteriormente, é rota-evaporado. $\mathrm{Na}$ sequiência, o filme fino resultante é hidratado. Através de liofilização do preparado aquoso obtem-se o produto comercial na forma de sólido altamente poroso. O tempo de vida é de aproximadamente 2 anos. Apesar do potencial desta formulação, existem numerosos pro- blemas industriais associados aos processos de obtenção desses filmes finos que oneram o uso comercial em TFD. Alguns desses problemas são: dificuldade de formar lipossomos com as características desejadas de maneira reprodutível, inclusive no processo de reidratação devido à dificuldade de solubilização completa; dificuldade para manter a estabilidade dos produtos em função do processo de manufatura; elevado tempo de processo; etc. Dificuldades associadas à segurança também podem ocorrer, provocadas pelo acúmulo de produtos de degradação, estes gerados durante a fabricação ou armazenamento.

Neste sentido, existem preocupações de buscar novos processos robustos de manufatura de materiais lipossômicos, ou outros, para serem usados em medicamentos novos para aplicações em TFD. Uma forma é o lipossomo produzido a partir de pó fino: uma mistura contendo fármaco, tampão, material anfifílico e antioxidantes é solubilizada em um solvente volátil adequado que é a seguir evaporado rapidamente. Devido à elevada área superficial do pó resultante, o processo de reidratação é mais fácil.

Além de lipossomos, polímeros com características anfóteras também são comercializados com fármacos para TFD. Por exemplo, o polietileno glicol é um componente do Levulan ${ }^{\circledR}$ Kerastick e do Foscan $^{\circledR}$

\section{ALGUNS MEDICAMENTOS PARA TFD}

Atualmente diversos compostos com características para aplicação em TFD estão sob investigação, dentre os quais podem ser citados: porfirinas expandidas, clorinas (um dos anéis pirólicos oxidado), bacterioclorinas (dois anéis pirólicos oxidados), ftalocianinas, naftalocianinas, purpurinas e outros ${ }^{6,7,12,24}$. Porém, entre testes bem sucedidos (in vitro e in vivo) até a comercialização de um medicamento aprovado pelas autoridades de saúde, a distância é grande. A seguir são abordados aspectos dos três únicos medicamentos aprovados para uso em TFD pela FDA (Photofrin ${ }^{\circledR}$, Levulan ${ }^{\circledR}$ Kerastick e Visudyne $^{\circledR}$ ) e de mais dois que estão sob análise (Foscan ${ }^{\circledR}$ e o MACE).

\section{i) Photofrin ${ }^{\circledR} 18$}

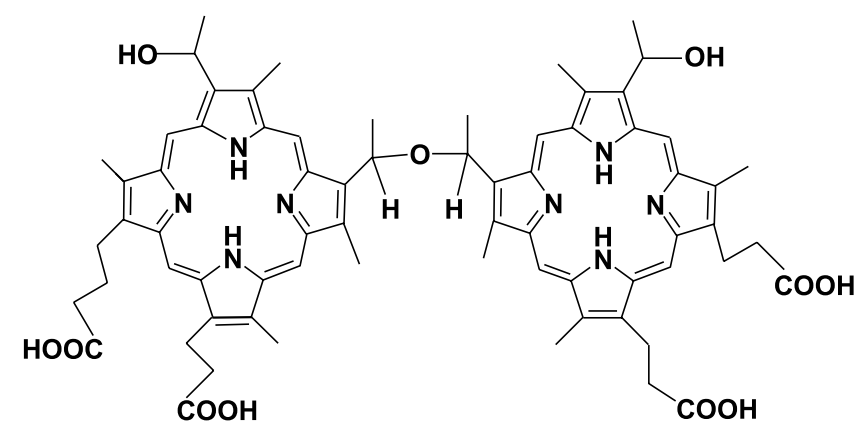

Esquema 2. Medicamento Photofrin ${ }^{\circledR}$

O Photofrin ${ }^{\circledR}$ tem como princípio ativo uma mistura complexa de oligômeros cuja composição exata até hoje não é bem definida. Para injeção a mistura é chamada de porfimer sodium. Trata-se de oligômeros de hematoporfirina cuja extensão não é uniforme, sendo detectados dímeros ${ }^{31}$, trímeros ${ }^{32}$ e 9 -meros ${ }^{33}$. A maioria das ligações entre as unidades é de éter, existindo ainda a de éster ${ }^{34}$ e carbonocarbono $^{35}$. O composto na forma dimérica com a ligação tipo éter é mostrado no Esquema 2. Apesar de várias propriedades benéficas, o Photofrin ${ }^{\circledR}$ apresenta desvantagem farmacocinética, ou seja, demora a ser eliminado do corpo (o tempo de meia vida varia bastante, sen- 
do aproximado a $250 \mathrm{~h}$ ). Acumula na pele ocasionando fotossensibilidade, principalmente sob sol forte, que pode durar mais de seis semanas. Além disso, a proporção mais efetiva de Photofrin ${ }^{\circledR}$ incorporado ao tecido doente em relação ao saudável ocorre, aproximadamente, em 2 dias após a injeção da droga provocando, eventualmente, a necessidade de hospitalização do paciente dois dias antes da irradiação (proteção contra a luz). Apesar dos desconfortos citados, essas desvantagens são ínfimas quando comparadas aos efeitos colaterais dos métodos clássicos de tratamento de câncer. Uma desvantagem adicional, que limita a aplicação mais abrangente para TFD em tumores grandes, é o comprimento de onda da luz (em $630 \mathrm{~nm}$ ) necessário à fotoexcitação, fazendo com que a penetração de luz no tecido seja limitada a poucos milímetros.

O material, sólido escuro meio avermelhado, é reconstituído via adição de solução aquosa com $5 \%$ de dextrose ou com $0,9 \%$ de cloreto de sódio $(31,8 \mathrm{~mL}$ para $75 \mathrm{mg}$ de porfimer sodium, totalizando aproximadamente $37,5 \mathrm{~mL}$, ou seja, $2,5 \mathrm{mg} / \mathrm{mL}$ ). A solução resultante, de $\mathrm{pH}$ entre 7 e 8 , deve ser usada imediatamente. A dose recomendada é $2 \mathrm{mg} / \mathrm{kg}$ do paciente. A infusão é feita lentamente (entre 3-5 min) diretamente na veia. Após 40 a $50 \mathrm{~h}$ faz-se uso do laser com difusor de fibra óptica cilíndrica OPTIGUIDE ${ }^{\circledR}$. O medicamento foi aprovado pela FDA para o tratamento de câncer no esôfago e pulmão (endobrônquios). No esôfago a dose de luz é $300 \mathrm{~J} / \mathrm{cm}$ de tumor (tempo de exposição $12 \mathrm{~min}$ e $30 \mathrm{seg}$ ) e no pulmão é $200 \mathrm{~J} / \mathrm{cm}$ ( 8 min e 20 seg). Após 96 a 120 h da infusão, o exame, via endoscopia ou broncoscopia, irá avaliar a necessidade de uma segunda aplicação de laser (com a mesma dose de luz) para eliminação de resíduos do tumor ${ }^{7,18}$.

\section{ii) Levulan ${ }^{\circledR}$ Kerastick (hidrocloreto do ácido aminolevulínico - ALA HCl) ${ }^{20}$}

O princípio ativo deste medicamento é obtido a partir do ácido $\delta$-aminolevulínico - ALA (ácido 5-amino-4-oxopentanóico), cujo fabricante é o DUSA Pharmaceuticals. O ALA $\mathrm{HCl}$, na forma de cloridrato, é um sólido branco, bastante solúvel em água e ligeiramente em etanol. Usado como solução tópica a $20 \%$ de uma mistura de $354 \mathrm{mg}$ de ALA $\mathrm{HCl}, 1,5 \mathrm{~mL}$ de etanol em água (48\% v/v) e polietileno glicol (estabilidade limitada a $2 \mathrm{~h}$ após a mistura).
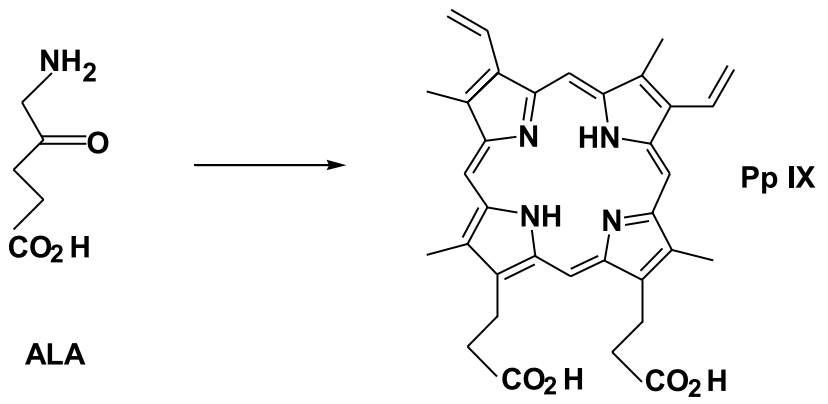

Esquema 3. Medicamento Levulan ${ }^{\circledR}$ Kerastick

Quando aplicado na pele, o ALA (pró-droga que é o material de partida para todas as porfirinas in vivo) é ciclizado por biossíntese, gerando a protoporfirina IX (Pp IX) que é a espécie fotoativa (Esquema 3). Após 14 a $18 \mathrm{~h}$ a Pp IX, formada na pele, é excitada através de lâmpada azul (BLU-U $\left.{ }^{\circledR}\right), 400-500 \mathrm{~nm}, 10,9 \mathrm{~J} / \mathrm{cm}^{2}$ (17 min). O tempo de meia vida em humanos foi de $0,70 \pm 0,18 \mathrm{~h}$ e $0,83 \pm 0,05 \mathrm{~h}$ após dose oral e intra-venosa, respectivamente. Recomenda-se evitar luz prolongada ou forte por, no mínimo, $40 \mathrm{~h}$. Usada no trata- mento de lesões pré-câncer de pele, na face e escalpo (Keratosis actínica $)^{6,7}$, em câncer de bexiga em fases I e II, acne e outras ${ }^{20}$.

\section{iii) meta-Tetra hidroxifenilclorina (m-THPC) ${ }^{36}$}

O medicamento que usa o m-THPC (Esquema 4) é conhecido por Foscan ${ }^{\circledR}$ (nome comercial) e Temoporfin ${ }^{\circledR}$ (nome genérico). É uma droga totalmente sintética análoga à meso-tetrafenilporfirina, um dos compostos modelos mais simples de porfirinas. Apesar de molécula simples, devido à rotação da ligação fenil-porfirina, temse 4 atropisômeros. No entanto na temperatura corpórea $\left(\sim 37^{\circ} \mathrm{C}\right)$, a rotação desta ligação é suficientemente rápida de modo a impedir que componentes biológicos reconheçam e façam distinções entre estas conformações espaciais. Estudos demonstraram que a atividade fotodinâmica para TFD é mais acentuada com o m-THPC que com o Photofrin ${ }^{\circledR}$. O m-THPC possui maior tempo de vida de estado triplete (portanto forma maior quantidade $\mathrm{de}^{1} \mathrm{O}_{2}$ ), maior absortividade molar $\left(\varepsilon_{652}=2,24 \times 10^{4} \mathrm{~cm}^{-1} \mathrm{M}^{-1}\right)$, maior hidrofobicidade (levando a uma maior incorporação celular), maior seletividade e pode ser excitado em um comprimento de onda maior (652 nm). Contudo, a fotossensibilidade na pele, causada pelo m-THPC, é apenas ligeiramente menor que aquela provocada pelo Photofrin ${ }^{\circledR}$. Devido à sua hidrofobicidade, o m-THPC é formulado em polietilenoglicol 400 (PEG):etanol:água, (3:2:5, v:v:v) para usos clínicos. O formulado de Foscan ${ }^{\circledR}$, um pré-dissolvido de m-THPC, usa propilenoglicol: etanol, (6:4, v:v $)^{6,7,29}$. Essa droga, desenvolvida pela Scotia Pharmaceuticals, está sendo analisada pela FDA para uso no tratamento de câncer de cabeça e pescoço, principalmente como paliativo para pacientes onde a cirurgia e radioterapia não podem ser apli$\operatorname{cadas}^{7,36}$.
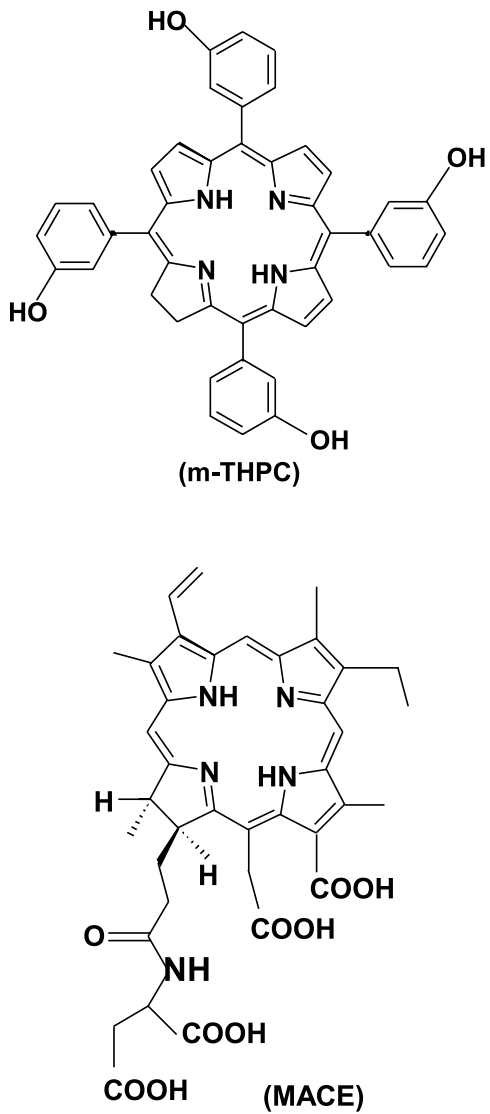

Esquema 4. Medicamento meta-tetra hidroxifenilclorina (m-THPC) e o mono-laspatil clorina e6 (MACE) 


\section{iv) mono-Laspatil clorina e6 (Npe6 ou MACE)}

MACE é uma clorina altamente solúvel em água que absorve em $654 \mathrm{~nm}\left(\varepsilon=4,0 \times 10^{4} \mathrm{~cm}^{-1} \mathrm{M}^{-1}\right)$. O rendimento quântico de oxigênio singlete é 0,77 e o de fotobranqueamento é $8,2 \times 10^{-4}$ (em tampão fosfato) e $1,6 \times 10^{-3}$ (em solução de sisteína). Apresenta efetividade in vitro e in vivo com baixa fotossensibilidade na pele, provavelmente por causa da sua rápida eliminação do corpo ${ }^{6,12}$ (Esquema 4).

\section{v) Visudyne ${ }^{\circledR}$. BPDMA ${ }^{21}$}

O composto BPDMA (Esquema 5) é uma clorina (um dos anéis pirólicos da porfirina oxidado). Sua síntese é feita a partir da reação de Diels-Alder entre a porfirina natural Pp IX com dimetilacetilenodicarboxilato, rendendo uma mistura equimolar de dois regioisômeros benzoporfirínicos (um com grupo benzo no anel A e outro no anel B). Os produtos (tipo clorina) apresentam banda Q em $666 \mathrm{~nm}$, porém o tratamento com base (amina) fortemente impedida, como a DBU (1,8-diazabiciclo[5,4,0]-7-undeceno), resulta em produtos que apresentam deslocamento batocrômico (absorção na região de 690 $\mathrm{nm}$ ). A reação do isômero de anel-A com $\mathrm{HCl}$ provoca a hidrólise de um dos grupos propil éster (ligado ao anel C ou D), acarretando o produto final BPDMA (monoácido). Este é uma mistura de dois regioisômeros: BPDMA (grupo ácido junto ao anel C) e BPDMA (grupo ácido junto ao anel D). Adicionalmente, cada regioisômero é uma mistura racêmica de dois enantiômeros (carbonos assimétricos junto ao grupo benzo), resultando, portanto, quatro compostos em quantidades iguais. Apesar de mistura, comprovou-se que a mesma é clinicamente apropriada para TFD. Após aplicação, o ácido se metaboliza, parcialmente, no corpo humano para o diácido, resultando no mínimo seis compostos ${ }^{5,12}$. Estudos biológicos demonstraram que a atividade fotodinâmica em formulações lipossomais, a forma mono-ácida é superior à di-ácida e à di-éster ${ }^{12}$.

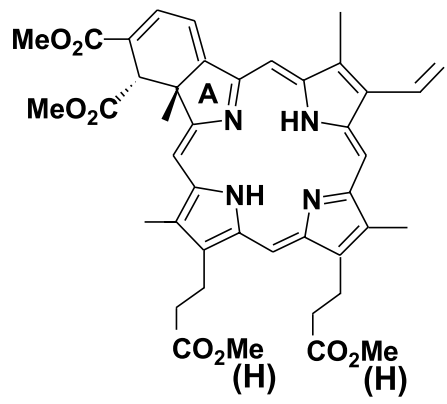

\section{Esquema 5. Medicamento Visudyne $e^{\circledR}$}

BPDMA apresenta as seguintes propriedades físico-químicas em metanol ${ }^{26,37}$ : coeficiente de absortividade $3,4 \times 10^{4} \mathrm{~cm}^{-1} \mathrm{M}^{-1}$ (ao redor de $690 \mathrm{~nm}$ ); rendimento quântico de fluorescência de 0,105 e 0,038 na presença de $\mathrm{N}_{2}$ e $\mathrm{O}_{2}$, respectivamente e rendimento quântico de conversão entre sistemas de 0,71 e 0,79 na presença de $\mathrm{N}_{2}$ e $\mathrm{O}_{2}$, respectivamente; energia do estado triplete igual a $26,9 \mathrm{kcal} / \mathrm{mol}$; rendimento quântico de oxigênio singlete de 0,76 e rendimento de fotobranqueamento de $2,7 \times 10^{-5}$ (em tampão fosfato) e de $2,1 \times 10^{-4}$ (em soro fetal de bovino). Assim, a alta absorção de luz em uma região próxima ao infra-vermelho, o baixo rendimento de fotobranqueamento (boa fotoestabilidade) e a alta formação de oxigênio singlete conferem ao BPDMA boas qualidades fototerapêuticas.

O conteúdo de BPDMA (sólido de cor preta esverdeada) em ampolas de Visudyne ${ }^{\circledR}$ é de $15 \mathrm{mg}$. Na reconstituição, o terapeuta adiciona $7 \mathrm{~mL}$ de água, formando aproximadamente $7,5 \mathrm{~mL}$ de solução, ou seja, composição de $2 \mathrm{mg} / \mathrm{mL}$. Esse material deve ser protegido da luz e usado dentro de $4 \mathrm{~h}$, sendo recomendada a inspeção visual de material particulado ou descolorido antes da aplicação. Quanto aos efeitos colaterais, o BPDMA apresenta fotossensibilidade na pele muito menor que o Photofrin ${ }^{\circledR}$ e tem tempo de meia vida de $6 \mathrm{~h}$ em seres humanos (excretado principalmente pelas fezes) ${ }^{21}$.

Para o tratamento da degeneração macular com Visudyne ${ }^{\circledR} \mathrm{o}$ tempo, entre a infusão e a iluminação (direta ao olho), é de 5 a 10 min através de laser não térmico (dose de luz recomendada de $50 \mathrm{~J} / \mathrm{cm}^{2}$ de lesão neovascular com uma intensidade de $600 \mathrm{~mW} / \mathrm{cm}^{2}$; tempo aproximado de $83 \mathrm{seg}$ ). Dependendo da necessidade, efetua-se 3 a 4 aplicações no primeiro ano ${ }^{7,9,21}$. Para tumores, os testes com BPDMA apontaram que o tempo ótimo para iluminação é de 30 a 150 min após a administração ${ }^{38}$ enquanto que para o Photofrin ${ }^{\circledR}$ é de dois dias.

\section{CONSIDERAÇÕES FINAIS}

As aplicações da TFD no tratamento de doenças diversas são bastante amplas. A acentuada corrida em busca de novas drogas fotoativas acarretou no desenvolvimento e aprovação de dois medicamentos notáveis, o Photofrin ${ }^{\circledR}$ e Visudyne ${ }^{\circledR}$. O forte impacto, junto à área médica, proveniente dos resultados extraordinários observados com o Visudyne ${ }^{\circledR}$ no tratamento de doenças da mácula, e a perspectiva deste e outros fármacos similares serem utilizados contra outras moléstias, têm estimulado fortemente as pesquisas na área de TFD. Adicionalmente aos esforços para o combate direto do câncer, a TFD também pode ser utilizada como método de diagnóstico precoce, uma vez que muitas das drogas usadas, além de apresentarem propriedades tumor-seletivas, também exibem forte emissão de fluorescência.

\section{AGRADECIMENTOS}

Ao CNPq e à Fundação Araucária/PR pelo auxílio financeiro. Ao prof. Dr. David Dolphin pela oportunidade de trabalhar em seus laboratórios na UBC e na QLT.

\section{REFERÊNCIAS}

1. Ferreira, A.B.H.; Novo Dicionário Aurélio, $1^{\mathrm{a}}$ ed., Ed. Nova Fronteira S.A.: Rio de Janeiro, 1975.

2. Folha de São Paulo, Brasil, 11/Junho/2000, C3.

3. http://www.inca.org.br, acessada em Maio 2001.

4. Levy, J.G.; Tibtech. 1995, 13, 14.

5. Sternberg, E.; Dolphin, D.; Curr. Med. Chem. 1996, 3, 239.

6. http://www.bmb.leeds.ac.uk/pdt, acessada em Maio 2001.

7. http://www.fda.gov/cder, acessada em Maio 2001.

8. Voughan, D.; Arbury, T.; Oftalmologia Geral, Ed. Atheneu: São Paulo, 1990, p. 186.

9. http://www.epm.br/ofta/fotodinamica, acessada em Maio 2001.

10. http://www.liv.ac.uk, acessada em Maio 2001.

11. The Merck Index; Budavari, S., ed.; Merck \& Co. Inc.: EUA, 1989.

12. Sternberg, E.D.; Dolphin, D.; Brückner, C.; Tetrahedron 1998, 54, 4151.

13. Raab, O.; Z. Biol. 1900, 39, 524.

14. Bonnett, R.; Rev. Contemp. Pharmacother. 1999, 10, 1.

15. Von Tappeiner, H.; Muench. Med. Wochenschr. 1903, 47, 2024.

16. Lipson, R.L. Em Proceedings of the $9^{\text {th }}$ International Cancer Congress; Tokio, Japan, 1966.

17. Dougherty, T.J.; Mang, T.S.; Photochem. Photobiol. 1987, 46, 67.

18. http://www.photofrin.com, acessada em Junho 2001.

19. http://www.qlt-pdt.com, acessada em Junho 2001.

20. http://www.dusapharma.com, acessada em Julho 2001

21. http://www.visudyne.com, acessada em Julho 2001.

22. Machado, A.E.H.; Quim. Nova 2000, 23, 237.

23. Wilson, P.C. Em Photosensitizing Compounds: their Chemistry, Biology and Clinical Use; Wiley Interscience: Chichster, 1989, p. 73.

24. Boyle, R.W.; Dolphin, D.; Photochem. Photobiol. 1996, 64, 469. 
25. Hadjur, C.; Wagnières, G.; Monnier, P.; van den Bergh, H.; Photochem. Photobiol. 1997, 65, 818 .

26. Aveline, B.M.; Hasan, T.; Redmond, R.W.; J. Photochem. Photobiol. 1995, B30, 161 .

27. Aveline, B.M.; Redmond, R.W.; Photochem. Photobiol. 1999, 69, 306.

28. Margalit, R.; Shaklai, N.; Cohen, S.; Biochem. J. 1983, 209, 547.

29. Dolphin, D.; The porphyrins, Academic Press Inc: EUA, 1978, part C, vol V.

30. Pasternak, R.; Huber, P.R.; Boyd, P.; Engasser, G.; Francesconi, L.; Gibbs, E.; Fasella, P.; Venturo, G.C.; Hinds, L.C.; J. Am. Chem. Soc. 1972, 94 4511.

31. Bellineier, D.A.; Ho, Y.H.; Pandey, R.K.; Missert, J.R.; Dougherty, T.J.; Photochem. Photobiol. 1989, 50, 221.
32. Mironov, A.; Nizhnik, A.; Nochel, A.; Photochem. Photobiol. 1990, 4, 297.

33. Pandey, R.K.; Siegel, M.M.; Tsao, R.; McReynolds, J.H.; Dougherty, T.J.; Biomed. Environ. Mass Spectrom. 1990, 19, 405.

34. Kessel, D.; Thompson, P.; Musselman, B.; Chang, C.K.; Photochem. Photobiol. 1987, 46, 563.

35. Pandey, R.K.; Shiau, F.; Medforth, C.J.; Dougherty, T.J.; Smith, K.M.; Tetrahedron Lett. 1990, 31, 789.

36. http://www.scotia-holdings.com, acessada em Junho 2001

37. Aveline, B.; Hasan, T.; Redmond, R.; Photochem. Photobiol. 1994, 59, 328.

38. Richter, A.M.; Waterfield, E.; Jain, A.K.; Smits, C.; Levy, J.G.; Photochem. Photobiol. 1993, 57, 1000. 